Rabaska

Revue d'ethnologie de l'Amérique française

\title{
Centre d'études lousianaises (Université de Louisiane à Lafayette)
}

\section{Nathan Rabalais}

Volume 18, 2020

URI : https://id.erudit.org/iderudit/1072965ar

DOI : https://doi.org/10.7202/1072965ar

Aller au sommaire du numéro

Éditeur(s)

Société québécoise d'ethnologie

ISSN

1703-7433 (imprimé)

1916-7350 (numérique)

Découvrir la revue

Citer ce document

Rabalais, N. (2020). Centre d'études lousianaises (Université de Louisiane à

Lafayette). Rabaska, 18, 452-454. https://doi.org/10.7202/1072965ar d'utilisation que vous pouvez consulter en ligne.

https://apropos.erudit.org/fr/usagers/politique-dutilisation/ 


\section{ÉTATS-UNIS}

Centre d'études lousianaises

(Center for Louisiana Studies)

Université de Louisiane à Lafayette

PO Box 43558

400 E. St. Mary Blvd, \# 313

Lafayette, LA 70504
Téléphone : (337) 482-6027

Courriel : cls@louisiana.edu

Toile : louisianastudies.louisiana.edu

\section{Mandat et collections}

Le Centre d'études louisianaises (CÉL) accueille dans ses archives du patrimoine cadien et créole des collections audiovisuelles qui demeurent la source première de la musique traditionnelle du sud de la Louisiane. Il continue de mettre ces enregistrements à la disposition du public et d'organiser des festivals et des spectacles spéciaux, des émissions de télévision et de radio. Le CÉL participe toujours à la production des Festivals acadiens et créoles, qui a lieu chaque année durant la deuxième fin de semaine d'octobre. Il collabore avec le College of Liberal Arts et d'autres organisations locales à des projets qui concernent l'histoire et la culture de l'Amérique française.

Parmi les collections françaises acquises, augmentées et cataloguées en 2019, signalons : - Warren Perrin, avocat, militant culturel : entrevues avec des soldats francophones, enregistrements en français pour des visiteurs francophones au Musée acadien d'Erath ; • Jason Theriot, historien : enregistrements de terrain, anciens combattants francophones ; • Barry Ancelet, folkloriste : enregistrements de terrain, (env. 1970-2020) ; numérisation des bandes sur bobines et des diapositives ; $\bullet$ Randy Falcon, accordéoniste, facteur d'accordéon : entrevues avec des musiciens cadiens ; - Harry Trahan, musicien : performances, sessions d'improvisation; • Natacha Istre, documentariste : enregistrements informels de sa famille (années 1970) ; • Chez Nous Autres : émission de radio en français (années 1980). - Ajouts aux collections des enregistrements commerciaux : Johnnie Allen, Belton Richard, Joe Bonsall, entre autres ; $\bullet$ Chase Cormier, doctorant : enregistrements de terrain, histoire orale ; - Festivals acadiens et créoles : enregistrements des concerts (2019). - Parmi les nouveaux fonds d'images, nous comptons : - Lafayette Convention and Visitors' Center, musiciens et musiciennes ; les festivals, etc. - Greg Guirard, photographe : images du travail et la vie dans le Bassin Atchafalaya. - Nouveaux fonds vidéo : - Francis Comeaux : entrevues informelles à la maison (années 1980); • Rudi Markl : performances musicales ; • Marcelle Tessier, militante culturelle et journaliste : années 1970-1980);• Tommy Comeaux Endowed Chair in Traditional Music : performances musicales ; - Kristi Guillory, musicienne : performances musicales; • Willie Durisseau, violoneux créole : performances et entrevues. - Une nouvelle initiative, la Cajun Creole Covid Collection, parrainée par le CÉL, comprend des enregistrements de terrain avec des locuteurs natifs francophones en Louisiane en rapport avec les effets du coronavirus. 


\section{Projets}

Le Centre a organisé le colloque « Les Filles et les Femmes : The Role of Women in Cajun and Creole Music », en partenariat avec les Festivals acadiens et créoles à Lafayette en octobre 2019. Le CÉL a également organisé une série de conférences ouvertes au public. Parmi les communications, soulignons celle de Maria Zeringue sur le Mardi-Gras, de Jessica Dauterive sur le « Fais dodo » et de Clint Bruce sur le meurtre d'un planteur acadien par son esclave. Le CÉL a aussi parrainé les ateliers de « Bayou Culture Collaborative » organisés par John Sharp, directeur adjoint à la recherche, un programme en partenariat avec divers organismes louisianais visant à enseigner des méthodes pour documenter la culture et les savoirs traditionnels en Louisiane, en particulier les cultures francophones (cadienne et amérindienne) dans les régions côtières de la Louisiane.

Barry Ancelet, Amanda LaFleur et Francine Girard Lomheim travaillent à développer une grammaire descriptive du français louisianais et à transcrire des entretiens enregistrés pendant les années 1970 et 1980 qui sont dans les archives de folklore du CÉL. • M. Ancelet a aussi présenté sa communication « Recycler le passé pour créer l'avenir : le projet Caesar Vincent » à plusieurs congrès et à CBAF, Radio-Canada, Moncton, et aussi « Identités partagées entre l'Acadie du Nord et l'Acadie tropicale : Acadian Diaspora from Louisiana to Acadia », au Congrès mondial acadien, Université de Moncton, en août 2019. • Rick Swanson continue ses recherches sur les relations entre les Acadiens-Américains et les Afro-Américains dans le sud de la Louisiane entre 1770 et 1970 . Heather Stone poursuit son étude de l'histoire orale des peuples de l'Île de Jean-Charles. • Mark Rees dirige toujours le « Projet Nouvelle-Acadie », une recherche archéologique pour découvrir le cimetière des premiers immigrés acadiens en Louisiane (www.ucs.louisiana.edu/ mar4160/ nap.html). - Jordan Kellman, doyen et historien, continue ses recherches sur les voyages scientifiques français : il a publié « Recollet Naturalism and the Colonial Order in Seventeenth-century New France » dans Les Récollets en Amérique : traces et mémoire, dirigé par Paul-André Dubois (PuL, 2019). • Le directeur adjoint du CÉL, John Sharp, continue son travail sur les salles de danse en Louisiane, afin de documenter ces lieux où on jouait la musique cadienne et créole, parmi d'autres traditions. On peut suivre son progrès en ligne (www.LouisianaDancehalls.com).

Le Centre a accueilli cinq nouveaux chercheurs associés pour la période de 2020-2025 : Clint Bruce (Université Sainte-Anne), Jeffery Darensbourg (chercheur indépendant), Phebe Hayes (Université de Louisiane à Lafayette), Andy Horowitz (Tulane University) et Nathan Rabalais (Université de Louisiane à Lafayette).

\section{Publications}

Les Presses universitaires de la Louisiane (UL Press) ont publié Ô Malheureuse : French Writings by Louisiana Women, par Ashlee Michot; et Visages du féminin et esthétique du mythe chez Jean-Marie Adiaffi, par Amadou Ouedraogo.

\section{Thèses}

Sous la direction de Gaëtan Brulotte, Luckson Bonhomme a soutenu une thèse de doctorat : « La Bourgeoisie postcoloniale au miroir des auteurs et cinéastes 
francophones des Antilles, de l'Afrique subsaharienne et du Maghreb de 1960 à nos jours ». D'autres thèses sont en préparation : Rachel Doherty, « Racines de magie noire : icônes occultes dans la littérature de la diaspora acadienne du $\mathrm{XX}^{\mathrm{e}}$ siècle »; Pierre Ros « Poétique de l'image dans le roman policier »; et Sarah Smith, « [Re] Writing History in the Imaginary of Francophone Louisiana ».

NATHAN RABALAis 